\title{
Development, Characterization, and Validation of a Sensitive Primate-Specific Quantification Assay for Forensic Analysis
}

BioTechniques 34:314-322 (February 2003)

\author{
John C. Fox, Christopher \\ A. Cave, and James \\ W. Schumm \\ The Bode Technology Group, \\ Springfield, VA, USA
}

\begin{abstract}
Accurate human-specific DNA quantification is essential for forensic casework analysis. In this work, we describe a microplate-based quantification assay that utilizes the PCR amplification of human-specific TH01 primers. This method enables the reliable quantification of human DNA samples from 0.2 to $40 \mathrm{ng}$, even in mixtures with nonhuman DNA. Analysis of samples can be semi-automated using 96-well microplates and a spreadsheet-based concentration calculator for high-throughput demands. We have used this quantification method with more than 15000 forensic samples.
\end{abstract}

\section{INTRODUCTION}

Many amplification assays used with forensic evidence perform best within a narrow range of human DNA template concentration. For the most commonly used short tandem repeat multiplexes, including the PowerPlex ${ }^{\circledR}$ 16, 1.1, and 2.1 Multiplex Systems (Promega, Madison, WI, USA), AmpFLSTR ${ }^{\circledR}$ COfil$e^{\circledR}$, Profiler Plus ${ }^{\mathrm{TM}}$, and Identifiler ${ }^{\mathrm{TM}}$ PCR Amplification Kits (Applied Biosystems, Foster City, CA, USA), the preferred DNA template window is $0.5-2.0 \mathrm{ng}(4,6,11,12,15,20)$. If too little human DNA is included for amplifica- tion, then peak height imbalance or allele dropout can occur $(7,8,10)$. With too much human DNA, the appearance of artifacts such as increased stutter percentage, nonspecific band creation, and lack of non-template addition can increase the difficulty of interpretation (5).

For the evaluation of forensic casework samples, the DNA Advisory Board to the Federal Bureau of Investigation recommends primate-specific quantification rather than total DNA quantification for forensic casework applications (www.cstl.nist.gov/biotech/strbase/dabqas.htm). Samples obtained in the field may contain contaminating bacterial, fungal, or other nonhuman contributions to the total DNA in the sample. However, the performance of the amplification systems used for DNA typing depends on the presence of human DNA within a particular range rather than total DNA. Thus, improved methods for the precise, reliable, and quantifiable measurement of human DNA present are constantly being sought.

Many quantification assays are available to define the total amount of DNA present in a sample $(1,9,17,19$, 22,23). However, for primate-specific quantification, most commonly used methods depend on the determination of the amount of a defined repeated sequence within the D17Z1 locus of the sample $(24,25)$. Current techniques employ the cumbersome slot blot hybridization processes, followed by time-consuming film development or the use of expensive image analysis instruments $(3,16)$. These approaches have an approximate capacity of 40 samples per filter and require the analyst to be present for nearly all of the more than $4 \mathrm{~h}$ to complete the assay. While these approaches have been widely employed, a recent study with mixed stain analysis concluded that imprecision in primate-specific template quantification accounted for a large portion of the variability in sample amplification success rates among different laboratories (5).

The need for improved precision, plus the growing demand for highthroughput approaches, encouraged us to develop and characterize a novel method to quantify the primate-specific component of a DNA sample. Our method relies on the PCR amplification of a defined region of the human TH01 locus (4). Amplification using human-specific primers creates the dominant component of a sample, even in the presence of nonhuman sources of DNA. Following amplification, the products are labeled with PicoGreen ${ }^{\circledR}$ dye (Molecular Probes, Eugene, OR, USA), which binds almost exclusively to dsDNA and increases in fluorescence output upon binding. Thus, the assay may be performed in a microplate, and no separation steps are required. The amount of bound dye is measured with a fluorometer and compared to the fluorescent output from a set of DNA standards across the template range of interest. Quantitative output is transferred to a Microsoft ${ }^{\circledR}$ Excel $^{\circledR}$ spreadsheet that has been created to simplify and accelerate the data analysis. Various attributes of the primate-specific assay were compared with a commercial human-specific hybridization quantification method and a total dsDNA quantification method. 


\section{MATERIALS AND METHODS}

\section{Genomic DNA}

Human DNA (GenBank ${ }^{\circledR}$ accession nos. GM09947 and GM09948) was obtained from Coriell Laboratory (Camden, NJ, USA). Purified rhesus monkey, rabbit, Saccharomyces cerevisiae (BD Biosciences Clontech, Palo Alto, CA, USA), E. coli (Sigma, St. Louis, MO, USA), and Candida albicans (ATCC, Manassas, VA, USA) DNA was used for the species specificity studies.

\section{Quantification Protocols}

Concentrations of the nonhuman DNA samples were provided by manufacturers. Human DNA concentrations were confirmed by spectrophotometric absorbance measurements taken at 260 and $280 \mathrm{~nm}$ (Spectrophotometer DU 640; Beckman Coulter, Fullerton, CA, USA). All DNA dilutions were performed in $\mathrm{TE}^{-4}$ (10 mM Tris- $\mathrm{HCl}, \mathrm{pH}$ 8.0, 0.1 mM EDTA).
Total dsDNA quantification (called "total DNA assay" in this work) was performed by a modification of the method described in the PicoGreen product insert (13). Briefly, a 1000-fold dilution of the stock PicoGreen reagent was prepared as the working solution. Ninety-nine microliters of $\mathrm{TE}^{-4}$ were added to each well of a 96-well Cytoplate (Applied Biosystems), except to the wells containing the standards. DNA standards were prepared with $\mathrm{TE}^{-4}(40,20,10,7,4,2,1,0.7,0.4,0.2$, and $0.1 \mathrm{ng}$ ) in a total volume of $100 \mu \mathrm{L}$. After the standards were added to their assigned wells, $1 \mu \mathrm{L}$ sample DNA was transferred to the remaining wells. Finally, $100 \mu \mathrm{L}$ PicoGreen working solution were added to each well, followed by thorough mixing. After a 5-min incubation under aluminum foil, the microplate was loaded into a CytoFluor ${ }^{\circledR}$ 4000 Multi Well Plate Reader (PerSeptive Biosystems, Framingham, MA, USA). The assay was performed with a gain setting of 80 , excitation at $485 \mathrm{~nm}$, and emission at $530 \mathrm{~nm}$. The fluores- cence data were exported to an Excel spreadsheet template that compared the sample DNA to a linear plot generated by the standards. Each sample concentration was measured in $n g / \mu \mathrm{L}$.

Primate-specific quantification by slot blot hybridization was employed using the QuantiBlot ${ }^{\circledR}$ Human DNA Quantitation Kit (Applied Biosystems), according to the product insert, except that ChemiGlow ${ }^{\mathrm{TM}}$ chemiluminescent reagent (Alpha Innotech, San Leandro, CA, USA) was used as the detection reagent (16). Blots were exposed to Hyperfilm $^{\mathrm{TM}}$ ECL $^{\mathrm{TM}}$ (Amersham Biosciences, Piscataway, NJ, USA) and developed for $1 \mathrm{~h}$.

The primate-specific assay was performed in $25-\mu \mathrm{L}$ reactions containing 1 $\mu \mathrm{L}$ unknown DNA sample or known DNA standard at 40, 20, 10, 7, 4, 2, 1, $0.7,0.4,0.2$, or $0.1 \mathrm{ng} / \mu \mathrm{L}$, respectively, 0.3× TH01 Primer Pair (TH01 Silver STR Kit; Promega), $1 \times$ GoldST*R Buffer (Promega), and 0.75 U AmpliTaq Gold ${ }^{\circledR}$ Polymerase (Applied Biosystems). Amplification was per-

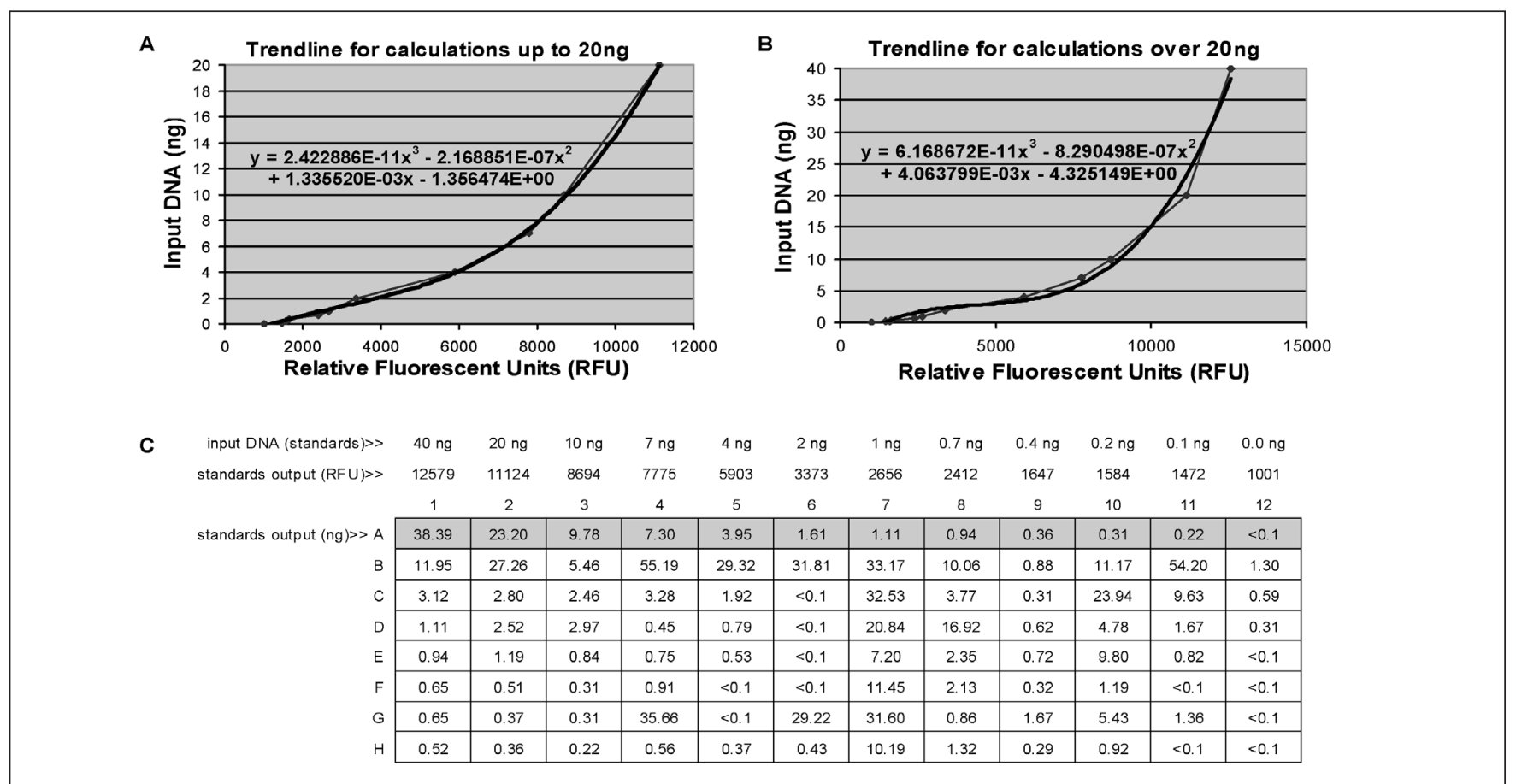

Figure 1. Excel spreadsheet used to calculate sample concentration. Fluorescence output data from CytoFluor 4000 Multi Well Plate Reader is electronically transferred to an Excel spreadsheet (data not shown). (A) Trendline is created using the fluorescent output from 0 to 20 ng DNA standards (Materials and Methods). The resulting equation is used to calculate unknowns up to $20 \mathrm{ng}$. (B) Trendline is created using fluorescent output from 0 to 40 ng DNA standards (Materials and Methods). The resulting equation is used to calculate unknowns greater than $20 \mathrm{ng}$. (C) This table displays the calculated DNA amount (ng) in each well of a microplate. The known quantities of input DNA standards are listed above the boxed region in the first row labeled "input DNA standards." The corresponding fluorescent output for each standard is displayed in the second row labeled "standards output (RFU)". Calculated values for the standards (ng), using the respective trendline equation, are displayed in row A (shaded). Values for unknown DNA samples in rows B-H are determined using the same trendline equations from their respective fluorescent output (data not shown). Sample calculations of less than 0.1 ng receive the designation " $<0.1$." 
formed using a GeneAmp ${ }^{\circledR}$ PCR System 9700 Thermal Cycler (Applied Biosystems) in 9600 emulation mode, with cycling conditions as follows: hold at $95^{\circ} \mathrm{C}$ for $11 \mathrm{~min}$, and then $96^{\circ} \mathrm{C}$ for $1 \mathrm{~min}$, followed by 10 cycles of $94^{\circ} \mathrm{C}$ for $30 \mathrm{~s}, 60^{\circ} \mathrm{C}$ for $30 \mathrm{~s}$ with a $68-\mathrm{s}$ ramp $(33 \%)$, and $70^{\circ} \mathrm{C}$ for $45 \mathrm{~s}$ with a 50 -s ramp (13\%); 20 cycles of $90^{\circ} \mathrm{C}$ for $30 \mathrm{~s}, 60^{\circ} \mathrm{C}$ for $30 \mathrm{~s}$ with a 60 -s ramp $(33 \%)$, and $70^{\circ} \mathrm{C}$ for $45 \mathrm{~s}$ with a $50-\mathrm{s}$ ramp $(13 \%)$; hold at $60^{\circ} \mathrm{C}$ for $30 \mathrm{~min}$, and then at $4{ }^{\circ} \mathrm{C}$ until the sample is stored at $4^{\circ} \mathrm{C}$ to $20^{\circ} \mathrm{C}$. Amplification product analysis was performed as described earlier for the total DNA assay, except that $2 \mu \mathrm{L}$ amplified DNA were mixed with $98 \mu \mathrm{L} \mathrm{TE}^{-4}$ before mixing with the PicoGreen working solution. A detailed protocol is available from The Bode Technology Group (Springfield, VA, USA) at www.bodetech.com.

The Excel spreadsheet for the semiautomated calculation of sample DNA concentrations employs the trendline function with a third-order polynomial fit of data points from the standard DNA series (Figure 1). A trendline created from the 20-ng and lower standards is used for the values less than or equal to $20 \mathrm{ng}$. A second trendline from all standards is used to calculate values greater than $20 \mathrm{ng}$. Each unknown DNA sample was quantified mathematically using the Excel-generated equations that fit these trendlines.

\section{RESULTS}

We utilized the DNA-binding prop- erties of the PicoGreen dye and the primate specificity of the TH01 amplification to develop a reliable and efficient method for DNA quantification in forensic samples. During development, we minimized the background fluorescence and determined the optimal cycle number, dye concentration, and primer concentration. We also demonstrated the species specificity of the assay.

\section{Assay Development: Optimization of Signal-to-Noise Ratio}

The PicoGreen dye preferentially binds dsDNA but also binds less efficiently to other products that are normally present in a forensic sample. In addition, nonspecific sources such as the microplate carrying the assay components, input primers, and unintended amplification products such as primer dimers may generate undesired background fluorescence.

To determine the maximum working range using the lowest concentration of the dye, we compared the use of $100 \%, 60 \%, 30 \%, 20 \%$, or $10 \%$, respectively, of the manufacturer-recommended concentration of the PicoGreen dye for dsDNA detection. The fluorescent signal produced in the absence of the DNA sample (i.e., the interfering background) was similar in each PicoGreen dye concentration that was tested. All tested dye concentrations (except 10\%) generated an increase in fluorescent output up to $40 \mathrm{ng}$ of the unamplified input DNA (Figure 2 ). We selected $20 \%$ of the recommended amount to make efficient use of the dye while providing linear signal-response over the range from 0.1 to 40 ng input dsDNA.

We compared Cytoplates (a low fluorescence microplate; Applied Biosystems) and the Falcon (a standard fluorescence microplate; $\mathrm{BD}$ Biosciences, San Jose, CA, USA) 96-well microplates containing only $\mathrm{TE}^{-4}$ buffer. In general, the Falcon microplates produced background fluorescent signals ranging from 900-1250 relative fluorescent units (RFU), while the Cytoplates produced 200-350 RFU of background fluorescence. The Cytoplates also displayed substantially more wellto-well consistency, making them more appropriate for this type of quantitative assay (data not shown).

We speculated that using less primer in the reaction would also generate lower background fluorescence by limiting the input primer directly and by generating fewer primer dimer artifacts. Therefore, we compared the amplification products using the amount recommended by the manufacturer versus $50 \%, 30 \%, 20 \%, 10 \%$, and $5 \%$ of that amount. Decreasing the input primer in the reaction had the desired effect of lowering background fluorescence (Figure 3 ). We selected $30 \%$ of the manufacturer-recommended amount for TH01 amplification because this lowered the negative-control amplification product background by approximately half, but still provided an increasing fluorescent signal according to product formation in the range from 0.1 to $40 \mathrm{ng}$ DNA template.

We speculated that if the primers

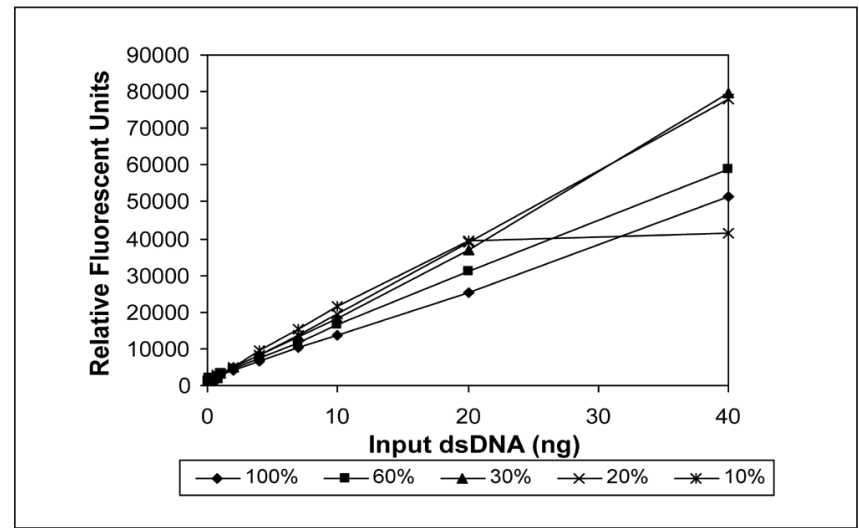

Figure 2. Effect of varying PicoGreen concentration. Percentages represent the proportion of the manufacturer's recommended amount of PicoGreen dye used in each assay.

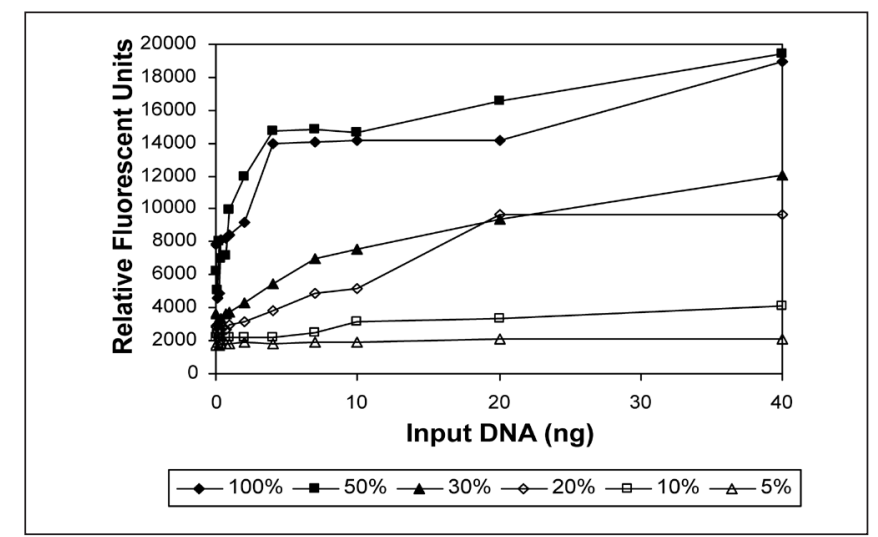

Figure 3. Effect of varying TH01 primer concentration. Percentages represent the proportion of the manufacturer's recommended amount of TH01 primer pair used in each assay. 


\section{Research Report}

generated little or no primer dimer during amplification, then increasing the number of amplification cycles would provide more amplification product, again increasing the discrimination between signals (i.e., amplified TH01 product) over all sources of background fluorescence. We compared 26, 27,28 , and 30 cycles and selected 30 cycles as our final assay condition (data not shown).

Assay Validation: Sensitivity, Reproducibility, Accuracy, and Precision

We determined the sensitivity of the assay using known sample amounts over a range from 0.1 to $40 \mathrm{ng}$ DNA. The GM09947 and GM09948 DNA templates were each tested twice over this entire range. Figure 4 displays the fluorescent output of the amplification products of each sample. Samples containing as much as 40 or as little as 0.2 ng DNA generated a signal that allowed for quantification. This covers the working range for most forensic samples in our laboratory.

The replicate titration series generated similar fluorescent output with each template amount. With small amounts of sample DNA, there was an approximate linear correlation between the sample input and fluorescent output. As template amount increased, it appears that either the PCR assay components or the PicoGreen dye itself became limiting and doubling the amount of tem- plate resulted in a less than doubling of the fluorescent signal from the amplified product.

While this assay is also useful for approximating the amount of DNA present in samples containing more than 40 ng DNA template, there is less precision with these higher amounts (data not shown). For optimal accuracy with highly concentrated samples, we recommend diluting the sample into the range from 1 to $40 \mathrm{ng}$ before the amplification step of the assay.

Concentrated samples of GM09947 and GM09948 human DNA, respectively, were tested with the assay 12 times each using either 1 or $10 \mathrm{ng}$ DNA templates, respectively. The assay was very reproducible. The average determination for the 10-ng sample of GM09947 was $10.34 \mathrm{ng}$ with an SD of $1.26 \mathrm{ng}$, and the average determination for the 10-ng sample of GM09948 DNA was 10.54 ng with an SD of $0.84 \mathrm{ng}$. For the 1-ng samples, the determinations were 1.09 with an SD of $0.14 \mathrm{ng}$, and 1.12 with an $\mathrm{SD}$ of $0.14 \mathrm{ng}$, respectively.

\section{Species Specificity}

Previous work demonstrated the primate-specific nature of TH01 amplification using the same primer sequences employed in this assay (4). In fact, DNA from primates closely related to humans (e.g., gorilla and chimpanzee) supports amplification while DNA from rhesus monkey and more distant- ly related primates, other mammals, fungi, and bacteria does not amplify (4). Our species-specificity analyses are consistent with these previously published results.

Several mixtures containing both human and nonhuman DNA templates were prepared. Nonhuman DNA sources consisted of E. coli, S. cerevisiae, rabbit, dog, and rhesus monkey. Human DNA and nonhuman DNA were mixed in the following amounts for testing: $0 \mathrm{ng}$ human with $40 \mathrm{ng}$ nonhuman; $0.4 \mathrm{ng}$ human with $39.6 \mathrm{ng}$ nonhuman; $2 \mathrm{ng}$ human with $38 \mathrm{ng}$ nonhuman; $10 \mathrm{ng}$ human with $30 \mathrm{ng}$ nonhuman; $20 \mathrm{ng}$ human with $20 \mathrm{ng}$ nonhuman; or $40 \mathrm{ng}$ human with $0 \mathrm{ng}$ nonhuman DNA for each nonhuman DNA, respectively. When $2 \mathrm{ng}$ or more human DNA were present, results in the presence or absence of nonhuman DNA were very similar (Figure 5). When less than 2 ng human DNA were present, the amplified product from 40 ng nonhuman DNA increased the background fluorescence equivalent to the amplification signal of approximately 1 ng human DNA. This effect became less significant to the interpretation of the result with the inclusion of increasing amounts of human DNA.

\section{DISCUSSION}

Human-specific quantification of DNA derived from sample material is

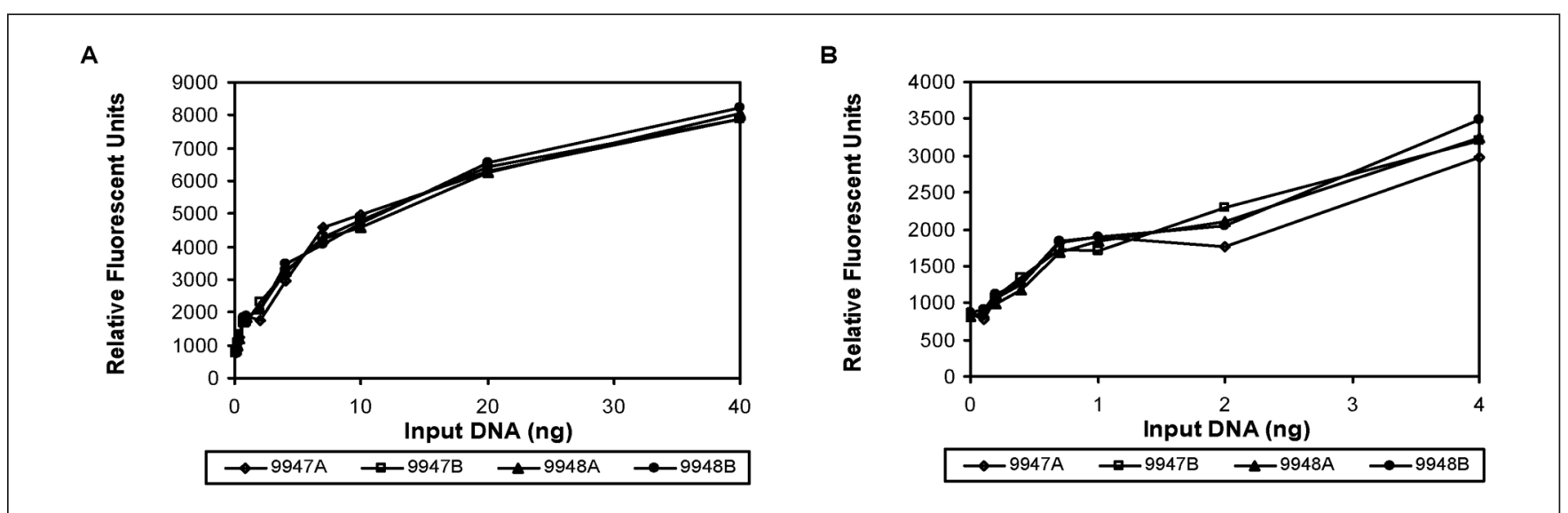

Figure 4. Sensitivity and reproducibility of GM09947 and GM09948 DNA. The DNA templates ranging from 0.1 to 40 ng of either sample GM09947 or sample GM09948 were each amplified twice. (A) Fluorescent output recorded over the entire template range. (B) Fluorescent output recorded over the template range from 0 to $4 \mathrm{ng}$. Note that the average RFU signal from the 0.2-ng, 0.1-ng, and negative-control sample extracts is $1063 \mathrm{RFU}$ with an SD of $57 \mathrm{RFU}$, 853 RFU with an SD of 54 RFU, and 844 RFU with an SD of 25 RFU, respectively. Thus, the sensitivity of the assay is 0.2 ng because the 0.1 -ng sample cannot be consistently distinguished from the negative control. 


\section{Research Report}

an important aspect of forensic DNA analyses. When dealing with forensic evidence, human and animal mixtures are relatively uncommon. However, certain kinds of evidence may be susceptible to bacterial contamination based on the age, storage, and location of the sample. Human-specific quantification methods assure the appropriate amount of DNA is prepared for multiplex amplification assays, even with samples compromised by bacterial or other DNA contaminants.

We developed, characterized, and validated a method to determine the amount of human DNA present in a sample that may also contain nonhuman DNA components. The method was designed to detect from 0.2 to 40 ng human DNA in a sample, an amount commonly seen in forensic work. Higher sample amounts can be accurately determined by the dilution of the sample before the amplification step, and lower amounts can be determined by the inclusion of up to eight times more sample extract volume in the amplification reaction (data not shown). The assay was designed to limit the fluorescent background from assay components such as microplates, primers, primer dimers, or the dye itself. In addition, we have demonstrated that the inclusion of nonhuman DNA from dog, rhesus monkey, rabbit, $S$. cerevisiae, $E$. coli, and C. albicans has little effect on interpretation. The likely cause of the minimal interference observed is the relatively inefficient binding of the PicoGreen dye to the denatured genomic DNA present in the assay.

A limitation to interpretation with this assay is its basic reliance on the amplification process for accurate quantification. Amplification inhibitors within a prepared DNA sample are expected to yield an underestimate of the amount of DNA in that sample. On the other hand, this "limitation" of the assay also offers an advantage versus other primate-specific quantification methods because the result may act as a better predictor of actual amplification yield expected with subsequent analysis using short tandem repeat multiplex kits. In practice, accurate primate-specific quantification is most helpful with DNA samples that contain large amounts of human DNA because these must be diluted properly before use. Samples that contain very little human DNA will often be used in their entirety, regardless of the precise amount present.

Important features of the primatespecific assay include the speed and compatibility with high-throughput analyses. All steps may be performed in a 96-well format. Thus, 12-channel pipettor or robotic transfer of 96 samples at a time (e.g., Hydra ${ }^{\mathrm{TM}}$ 96; Robbins Scientific, Sunnyvale, CA, USA) are used to accelerate workflow. The entire assay takes approximately $3.5 \mathrm{~h}$ to complete one plate of 84 samples and 12 standards. Of this, only about 1 $\mathrm{h}$ of analyst time is required. The remainder of the time is dedicated to the PCR amplification. Each additional plate of 84 samples can be added with approximately 45 additional minutes of setup and processing time.

In our current use of the primatespecific assay, the output of the fluorometer is exported to an Excel spreadsheet. The spreadsheet employs the Excel trendline function to calculate the template amount in each sample in a semi-automated fashion. These results are electronically transferred to a robot (BioRobot 9604; Qiagen, Valencia, CA, USA) that automates the dilution and transfer of all samples to a new microplate at the desired concentration. All samples starting with less than 1 $\mathrm{ng} / \mu \mathrm{L}$ in the original tray can be transferred without dilution. Thus, all the samples are "PCR-ready" at this point and can be transferred to PCR amplification trays via multichannel pipettors or the Hydra liquid handler.

All of these features make the assay compatible with the application to forensic casework. In fact, our laboratory processes hundreds of forensic cases each month using this assay. We have quantified more than 15000 sample preparations with the primate-specific assay in the past year and have found it to be very reliable in meeting our need for consistent quantification results.

This method can be performed without a fluorometer using an agarose gelbased detection scheme (data not shown). The visual comparison of amplified samples and amplified standards can be recorded following separation in a $1 \%$ agarose gel stained with $\mathrm{SYBR}^{\circledR}$ Green (Molecular Probes) (14). However, the working analysis range for gelbased sample detection is narrower than with fluorescence-based detection. Sample quantification can be estimated between the range from 0.2 to $10 \mathrm{ng}$ DNA.

\section{Comparison with Other DNA Quantification Systems}

We compared our primate-specific assay with a commercially available hybridization-based method and the total DNA fluorescent method, as described in the Materials and Methods section. The hybridization method allows for the simultaneous processing of 40 samples and eight DNA standards, which requires approximately $4.5 \mathrm{~h}$ to complete and demands the analyst's attention for nearly all of this time. With a 1-h film exposure time, quantification results over the full range from 0.1 to 40 ng DNA were achieved. Furthermore, the use of this method with up to $40 \mathrm{ng}$ rhesus monkey or rabbit DNA generated a signal equivalent to no more than 2 ng human DNA. Up to 40 ng $C$. albicans or E. coli DNA produced no detectable signal in this assay.

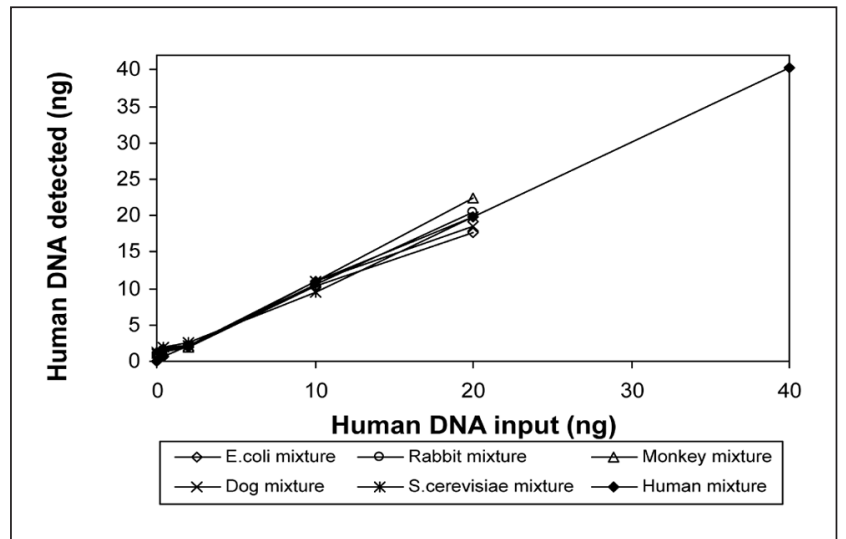

Figure 5. Human DNA detected in the presence of nonhuman DNA. Forty nanograms of total DNA were amplified in each case. The amount of human DNA included in each mixture is indicated. The filled diamonds indicate the fluorescent signal observed from human DNA alone. 


\section{Research Report}

When mixing $10 \mathrm{ng}$ each nonhuman DNA, respectively, with a 0.1 - to 40-ng titration of human DNA, we did not observe any interference with the accurate detection of human DNA, except for the slight decrease in the signals of 0.2 and $0.5 \mathrm{ng}$ human DNA template mixed with C. albicans.

The total DNA assay produced essentially linear quantification results over the range from 0.2 to $20 \mathrm{ng}$ DNA (data not shown). The 0.1 ng DNA template could not be distinguished from the negative control. The 40-ng DNA sample was essentially indistinguishable from the 20-ng DNA template, presumably because the dye saturation limit of the assay was reached using our modified protocol. This approach detected human, rhesus monkey, rabbit, $C$. albicans, and E. coli DNA with similar efficiencies. Therefore, all DNA mixtures that were tested were quantified as total input DNA template amounts. This result was expected because the assay measures total dsDNA rather than human-specific DNA.

We have demonstrated that our primate-specific assay is superior to other commonly used quantification methods. In particular, the sensitivity range, human specificity, and high-throughput-compatible format make it an extremely useful tool in the analysis of forensic DNA samples.

We are currently working to expand the range and sensitivity of the method. We have investigated the amplification of the highly repeated primate-specific Alu sequences that are dispersed throughout the human genome (2) in place of the TH01 locus of the current assay. Quantification based on the amplification of Alu sequences utilizes the high copy number of these repetitive insertions to achieve greater sensitivity while cutting cycle number from the assay time. Recently published works $(18,21)$ that describe Alu-dependent amplification techniques suggest that we will be able to complete the development and validation of this more rapid method.

\section{ACKNOWLEDGMENTS}

We wish to thank Michael Cariola for providing information regarding the success rates of this method in forensic casework applications. We thank Todd Bille for providing helpful criticism to improve the content and presentation of the manuscript.

\section{REFERENCES}

1.Ahn, S.J., J. Costa, and J.R. Emanuel. 1996 PicoGreen ${ }^{\circledR}$ quantitation of DNA: effective evaluation of samples pre- or post-PCR. Nucleic Acid Res. 24:2623-2625.

2.Batzer, M.A. and P.L. Deininger. 1991. A human specific subfamily of Alu sequences. Genomics 9:481-487.

3.Budowle, B., W.R. Hudlow, S.B. Lee, and L. Klevan. 2001. Using a CCD camera imaging system as a recording device to quantify human DNA by slot blot hybridization. BioTechniques 30:680-685.

4.Crouse, C.A. and J. Schumm. 1995. Investigation of species specificity using nine PCR based human STR systems. J. Forensic Sci. 40:952-956.

5.Duewer, D.L., M.C. Kline, J.W. Redman, P.J. Newall, and D.J. Reeder. 2001. NIST mixed stain studies \#1 and \#2: interlaboratory comparison of DNA quantification practice and short tandem repeat multiplex performance with multiple-source samples. J. Forensic Sci. 46:1199-1210

6.Frank, W.E., B.E. Llewellyn, P.A. Fish, A.K. Riech, T.L. Marcacci, D.W. Gandor, D. Parker, R.R. Carter, et al. 2001. Validation of the AmpFLSTR Profiler Plus ${ }^{\mathrm{TM}}$ PCR amplification kit for use in forensic casework. J. Forensic Sci. 46:642-646.

7.Goodwin, W., A. Linacre, and P. Vanezis. 1999. The use of mitochondrial DNA and short tandem repeat typing in the identification of air crash victims. Electrophoresis 20:1707-1711.

8.Greenspoon, S.A., P.J. Lytle, S.A. Turek, J.M. Rolands, M.A. Scarpetta, and M.A. Carr. 2000. Validation of the PowerPlex ${ }^{\circledR} 1.1$ loci for use in human identification. J. Forensic Sci. 45:677-683.

9.Hopwood, A., N. Oldroyd, S. Fellows, R. Ward, S.A. Owen, and K. Sullivan. 1997. Rapid quantification of DNA samples extracted from buccal scrapes prior to DNA profiling. BioTechniques 23:18-20.

10.LaFountain, M.J., M.B. Schwartz, P.A. Svete, M.A. Walkinshaw, and E. Buel. 2001. TWGDAM validation of the AmpF1STR Profiler Plus ${ }^{\mathrm{TM}}$ and AmpFLSTR COfiler ${ }^{\mathrm{TM}}$ STR multiplex systems using capillary electrophoresis. J. Forensic Sci. 46:1191-1198.

11.Micka, K.A., C.J. Sprecher, A.M. Lins, C.T. Comey, B.W. Coons, C. Crouse, D. Endean, K. Pirelli, et al. 1996. Validation of multiplex polymorphic STR amplification sets developed for personal identification applications. J. Forensic Sci. 41:582-590

12.Micka, K.A., E.A. Amiott, T.L. Hockenberry, C.J. Sprecher, A.M. Lins, D.R. Rabbach, J.A. Taylor, J.W. Bacher, et al. 1999. TWGDAM validation of a nine-locus and a four-locus fluorescent STR multiplex system. J. Forensic Sci. 44:1243-1257.

13.Molecular Probes. 2000. PicoGreen ${ }^{\circledR}$ dsDNA
Quantitation Reagent and Kits. Product Information, Molecular Probes, Eugene, OR.

14.Molecular Probes. 2000. SYBR ${ }^{\circledR}$ Green I Nucleic Acid Gel Stain. Product Information, Molecular Probes, Eugene, OR.

15.Moretti, T.R., A.L. Baumstark, D.A. Defenbaugh, K.M. Keyes, J.B. Smerick, and B. Budowle. 2001. Validation of short tandem repeats (STRs) for forensic usage: performance testing of fluorescent multiplex STR systems and analysis of authentic and simulated forensic samples. J. Forensic Sci. 46:647-660.

16.Perkin Elmer Life Sciences. 1996. QuantiBlot $^{\mathrm{TM}}$ Human DNA Quantitation Kit. Product Information, Perkin Elmer Life Sciences, Gaithersburg, MD.

17.Romppanen, E.L., K. Savolainen, and I. Mononen. 2000. Optimal use of the fluorescent PicoGreen ${ }^{\circledR}$ dye for quantitative analysis of amplified polymerase chain reaction products on microplate. Anal. Biochem. 279:111-114

18.Sifts, M.E., K. Both, and L.A. Burgoyne. 2002. A more sensitive method for the quantitation of genomic DNA by Alu amplification. J. Forensic Sci. 47:589-592.

19.Singer, V.L., L.J. Jones, S.T. Yue, and R.P. Haugland. 1997. Characterization of PicoGreen ${ }^{\circledR}$ reagent and development of a fluorescence-based solution assay for double stranded DNA quantitation. Anal. Biochem. 249:228238

20.Tomsey, C.S., M. Kurtz, F. Kist, M. Hockensmith, and P. Call. 2001. Comparison of PowerPlex $^{\circledR}$ 16, PowerPlex $^{\circledR} 1.1 / 2.1$ and ABI AmpF1STR Profiler Plus ${ }^{\mathrm{TM}} / \mathrm{COfiler}^{\mathrm{TM}}$ for forensic use. Croat. Med. J. 42:239-243.

21.Urban, C., F. Gruber, M. Kundi, F.G. Falkner, F. Dorner, and T. Hammerle. 2000. A systematic and quantitative analysis of PCR template contamination. J. Forensic Sci. 45:1307-1311.

22.Van Dyke, K. and C. Szustkiewicz. 1968. Automated systems for the fluorometric determination of nucleic acids by the ethidium bromide technique. Anal. Biochem. 23:109-116.

23.Vitzthum, F., G. Geiger, H. Bisswanger, H. Brunner, and J. Bernhagen. 1999. A quantitative fluorescence-based microplate assay for the determination of doubled stranded DNA using SYBR ${ }^{\circledR}$ green I and a standard ultraviolet transilluminator gel imaging system. Anal. Biochem. 276:59-64.

24.Walsh, P.S., J. Varlaro, and R. Reynolds. 1992. A rapid chemiluminescent method for quantification of human DNA. Nucleic Acids Res. 20:5061-5065.

25.Waye, J.S., L.A. Presley, B. Budowle, G.G. Shutler, and R.M. Fourney. 1989. A simple and sensitive method for quantifying human genomic DNA in forensic specimen extracts. BioTechniques 7:852-855.

Received 30 August 2002; accepted 4 December 2002.

\section{Address correspondence to:}

Dr. James W. Schumm

7364 Steel Mill Drive

Springfield, VA 22150, USA

e-mail:james.schumm@bodetech.com 